\title{
Sustainable Cities: Strategy and Indicators for Healthy Living Environments
}

\author{
Mohsen M. Aboulnaga ${ }^{1, *}$, Sabah Abdullah ${ }^{2}$ \\ ${ }^{1}$ Professor, University of Dubai, Dubai, UAE and Main Founder, Emirates Green Building Council \\ ${ }^{2}$ University of the Basque Country, Environmental Economics Unit, Institute for Public Economics, 48015 \\ Bilbao, Spain \& University of Bath, Department of Economics, Bath, UK \\ * Corresponding author. Tel: +971 506185217, PoBox 126166 Dubai, E-mail: mohsen_aboulnaga@yahoo.com
}

\begin{abstract}
The impact of climate change on our cities has been clearly manifested. Cities do not only consume most natural resources but also produce air pollution and generate great amount of waste and waste water. This paper focuses on sustainable cities strategies and indicators for the case of Santa Monica city, US using a set of 29 sustainable indicators for some years 1990-2006. The study sheds light on the application of some sustainable development (SD) indicator and suggests more applicable and specific data to further examine other cities sustainable programmes. The six thematic dimensions: sustainable, economic, equitable, social, viable and livable, where $62 \%$ of the 29 indicators are presented. Indeed, the review of some of the 29 indicators for Santa Monica shows the various levels of SD before and after the Sustainable City Program (SCP).
\end{abstract}

Keywords: Sustainable Cities, Strategies, Sustainable Development Indicators, Santa Monica.

\section{Introduction}

Over the past century, cities and towns using various urban systems were developed and built in inefficient ways based on traditional ways of activities and life styles. Consequently, such models drove production and consumption of resources inefficiently. Indeed, the urban sprawl is an urgent and persistent problem when world's natural resources are scarce and pressured by human settlement. Moreover, such pressures particularly related to carbon emissions in urban areas/ cities involve power generation, transport, and waste. Nevertheless, creating buildings and designing cities is one of the most complex and sophisticated tasks.

Cities pressure natural resources and consume large amounts of energy and water as well as emitting air pollutants and generating waste. All these activities pose potential risks to our economic, health and environmental wellbeing and the prime global concern at the present time is the effect of human activities upon climate change particularly related to urban areas. Several studies published by the United Nations Habitat showed that in 2007-2008 a major shift occurred where more than half the world's population was classified as urban dwellers $[1,2,3]$. Globally, the number of people living in towns and cities at the end of 2008, was estimated at 3.3 billion and this is expected to increase to five billion by 2030 [4,1]. However, the main challenges to such increases are the pressure on natural resources as well as utilities such as on energy, water as well as waste management and mobility. For instance, the recent United Nations Environment Programme (UNEP) data on global energy demand suggested that nearly 45 percent will increase by 2030 [5].

It is vital to efficiently plan our cities to be sustainable by developing strategies and policies to promote sustainability. Significantly, capturing sustainable development indicators at local as well as global levels is relevant since the climate changes and pollutions are global problems. Moreover, emphasis should be stressed when it comes to cities' consumption patterns and their impact on other neighboring regions and ecosystems. Also, the accountability and responsibility for all stakeholders to assist in monitoring consumption patterns and addressing the requirements for a sustainable city is needed. Additionally, adaptive policies to reduce, recycle and re-use consumer goods are important strategies for 
cities to achieve sustainability pathways [6]. As shown in Table 1, the list depicts some of the sustainable cities according to sustainable city network (SCN) 2007-2011 [7].

Table1. List of Sustainable Cities

\begin{tabular}{ccc}
\hline Australia \& Pacific & Americas & Europe \\
\hline Adelaide & Ottawa & Berlin \\
Ballarat & Vancouver & Bristol \\
Maleny & Niagara & Cambridge \\
Melbourne & Florida & Geneva \\
Auckland & Greensburg & Malmö \\
Wellington & Moraga & Rotterdam \\
& Santa Monica & Stockholm \\
& Philadelphia & \\
& Tuscon & \\
& San Francisco & \\
& San Jose & \\
& Seattle & \\
& Silicon Valley & \\
& Bogota & \\
& Chiapas & \\
& Curitiba &
\end{tabular}

In the next sub-section namely sustainable indicators (1.1), we discuss briefly some components of such strategies which some cities have integrated in their mandate to become sustainable.

\subsection{Sustainable Development Indicators (SDI)}

According to Tanguay, et.al (2010), sustainable development indicators (SDI) are used intensively to illustrate sustainable development pathways particularly applying actual assessment and monitoring systems [8]. The authors also argued that the exploitation of the SDI remains problematic because of general definition of sustainable development as outlined in the Brundtland report (WCED, 1987). SDI varies from one place to another but the main components are listed in Table 2. SDI variation in the present time compared to say twenty years ago can be attributed to the priorities set in meeting the environment, social, economic, political and technological objectives of the local and regional needs. A case in point is in the EU where new and old member countries are requested to revise their National sustainable development strategies (SDS) in line with the renewed EU SDS which is likely to increase the degree of cohesion in defining and monitoring SDIs. As mentioned previously, SDI can differ at local levels but must also be analyzed from a global perspective.

Table.2. Indicators used to measure the sustainability of a city

- Sustainable Development Policy \& Practice

- Biodiversity

- Climate Change

- Social Issues

- Energy

- Pollution

- Environment

- Urban Development

- Planning

- Transport

- Construction

- Waste Management

- Water 
Moreover, sustainable cities may vary due to the countries or regional sustainable strategies. Take the case of US where according to the latest report by the Sustainable Cities Index (SCI) the sustainable cities namely the City of Portland, Oregon, were analyzed according to four major indicators: clean technology, green building development, overall quality of life, and sustainability planning and management [9]. In the case of UK cities, the assessment focused less on the equitable dimension. For Europe, cities can and should not only be highly resource-efficient but also safe, healthy, pleasant, fulfilling and inspiring places to live. Based on a strategy paper (2007-2013) by the European neighborhood and partnership, it concluded that at city level, the local strategies for sustainability require active participation and commitment of the local community who can provide effective actions [10]. Moreover, the challenge for Europe's cities to achieve sustainability objectives their governments must allow cities maximum freedom to apply suitable tools at local level [6]. Indeed, indicators are increasingly developing into a vital tool of communicating information to decision-makers and the public in a straightforward and robust manner.

The motivation of this paper is to review several indicators that measure sustainability of cities by examining one case study found at a local level in the United States. Our attempt is to illustrate the practical application of such indicators at the local levels. In fact, the need to measure sustainable development (SD) is based on robust indicators or evaluation criteria [8]. The comparison of theoretical and practical approaches is essential in illustrating the robustness of such criteria.

In this vein, Shen et al. (2011) point out that among the available urban sustainability indicators there are no single set of indicators equally suitable to all cities or communities. They further suggest the use of consistent indicators for monitoring and comparison purposes due to the fact that such indicators will allow cities to have a common grid to share and apply successful tools and measures [11]. Zhang, He, and Wen (2003) recommend that for urban sustainability indicators (USI), in other words, city sustainable indicators should offer no less than: a) explanatory tools to translate the concepts of sustainable development into practical terms; b) pilot tools to assist in making policy choices to promote sustainable development; and c) performance assessment tools to decide how effective efforts have been established [12]. This paper is outlined in 4 parts: introduction as presented above, section 2, methodology and sub-section focusing Santa Monica city as a case study. Section 3, presents the results and discussions of the application of sustainable development indicators for the case of Santa Monica, and section 4 concludes.

\section{Methodology}

Many models address sustainable cities in different taxonomies. However, strategy and policy, and appropriate assessment tools at national planning levels should be firmly developed and implemented to improve the key indicators in order to ensure cities are sustainable at the local levels. In Moussiopolous et al. (2010) study, they developed a dynamic tool for the management of environmental, social and economic indicators to evaluate sustainability in urban areas. In their study, the case study of Greater Thessaloniki Area, in Greece was selected with a set of indicators included 88 indicators in 13 discrete thematic areas. Additionally, guidelines were recommended for developing communication among local stakeholders [13].

Shen et al. (2011) critically examined and compared different sustainable urbanization practices when selecting urban sustainability indicators [11]. They further stated that measuring sustainability in urban areas requires strong local socio-economic development and 
the key challenge for environmental managers and decision-makers is environmental decay. They further caution that indicators selected should be the ones that are essential and likely to produce the most accurate information about the status of practice. Tanguay et al, (2010) defined a number of SDI derived from 17 studies showing diverse conceptual frameworks and choices. In their study, a method, called SuBSelec, where 188 indicators extracted from the aforementioned 17 studies and reduced to 29 SDI. The SuBSelec strategy produced a new perspective to the debate related to the SDI selection. This is seen as a preliminary step aimed for planners and decision makers where a scientifically based and operational SDI Grid is established [8]. The authors acknowledge the subjective nature of this approach and believe that the classification allows the selection of recognized indicators which covers the various aspects of sustainable development broadly. Additionally, their conclusion is similar to Niemeijer and De Groot (2008) in that selection of indicators is invariably subject to arbitrary decisions at one phase of the process or another [14]. Such analyses demonstrate that current practices related to SDI cannot meet standard objectives and the need to obtain indicators which reflect local concerns.

In this study we follow the approach suggested by Tanguay et al. (2010) namely, Surveybased selection strategy (SuBSelec) which refers to 29 indicators divided into six dimensions: sustainable, liveable, equitable, social, economic and viable, for a given city [8]. The focus of next sub-section is to review and compare the Santa Monica Sustainable City Indicators (SCI) as found in SCP to the sustainable development indicators (SDI) given by these authors.

\subsection{The case study: Santa Monica}

In early 1990's the Santa Monica City Council took bold steps to address sustainability issues in the community adopting a Sustainable City Plan [15]. The Sustainable City Program (SCP) was initially proposed in 1992 by the City's Task Force on the Environment to ensure that Santa Monica could continue to meet its current needs-environmental, economic and social without compromising the ability of future generations to do the same. Such a programme comprised goals and strategies, for the City government and all sectors of the community. As shown in Table 3 (see Appendix) eight indicators' dimension with their respective categories were defined by the SCP. Indeed, the primary reason of selecting this city is because it boasts of comprehensive history to examine and discuss at local level. In reviewing the SCP, a span of several years ranging from 1990 to 2008 was selected, depending on the availability of data. In Table 4 (see Appendix), each indicator and the eight SD dimensions are depicted with the relevant notes for various years. It should be noticed that some indicators were not applied to all. For the comparison purposes the ratio between the years 2000 and 1990 were set to 1 for relative changes but not in absolute terms, this is because in some cases few years were not for 2000 and 1990 as explained above.

\section{Results and discussion}

This section exhibits the six dimensions: sustainable, economic, equitable, social, viable and livable, where $62 \%$ of the 29 indicators are presented. Indeed, the review of some of the 29 indicators for Santa Monica shows the various levels of SD before and after the SCP.

Fig.1 and Fig.2, illustrate the sustainable and economic dimensions respectively where in the year 1990 and 2000 greatly differs, where in 1990s the sustainable and economic situations were less than the year 2000. For the equitable dimension (Fig.3), it exhibits a better performance in 2000 compared to that of 1990 in terms of low crime rates and poverty levels. In Fig.4, the citizen participation increased nearly twice as those in 1990. Also, the rate of participation in municipal elections has slightly increased. 
The viable dimension as shown in Fig.5 exhibits this dimension in terms of quantity of waste recycled. In this dimension, the ratio increased from ratio 0.2 (1999) to 1 (2000). This can be attributed to number of waste produced and/or the increase in technology in recycling such waste.

For the livable dimension as shown in Fig.6, both indicators the GHG emission and household waste in 2000 have increased compared to 1990. This maybe explained due to increase in populations or socio-economic activities during this time. Again, the indicators are subjective particularly when population and other economic variables are not considered in the picture.

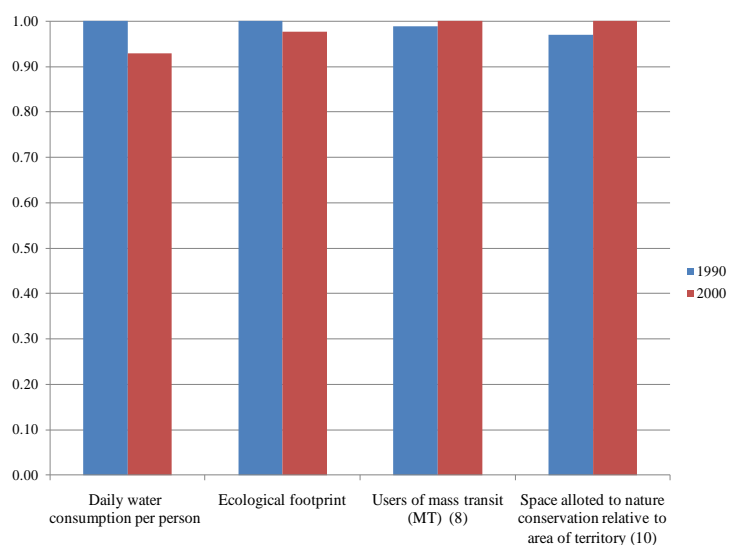

Fig.1 Sustainable Dimension

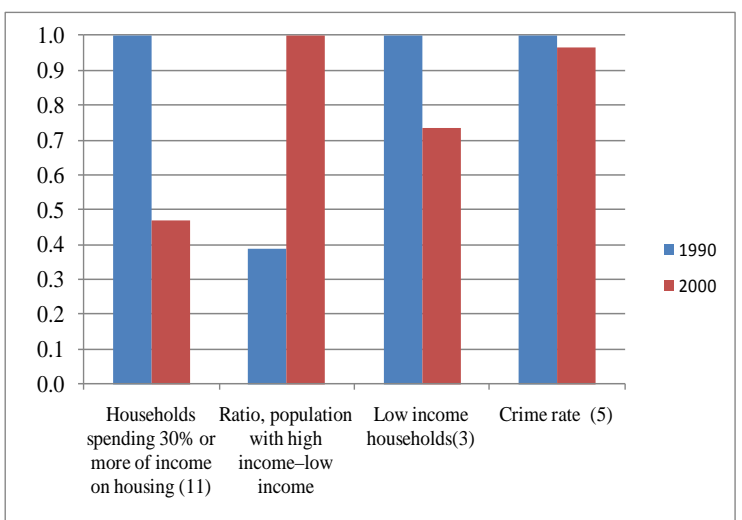

Fig.3 Equitable Dimension

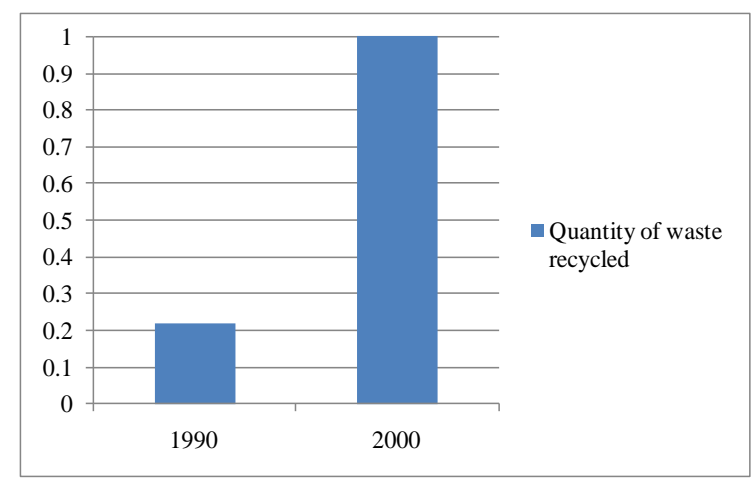

Fig.5 Viable Dimension

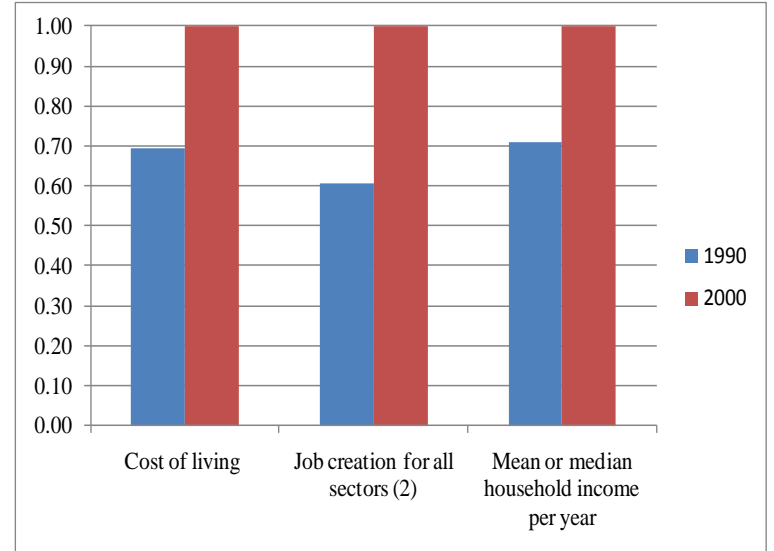

Fig.2 Economic Dimension

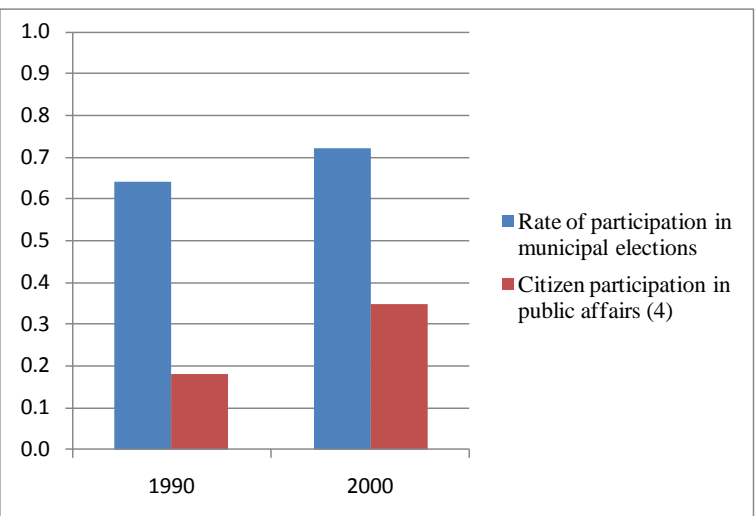

Fig.4 Social Dimension

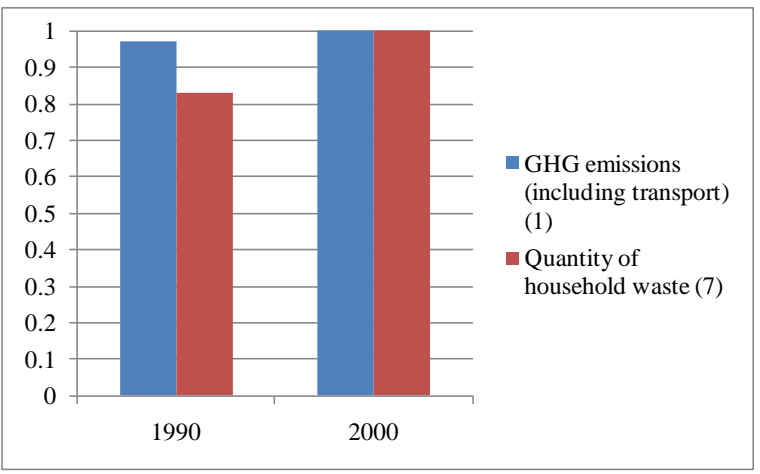

Fig.6 Livable Dimension 


\section{Conclusions}

In this paper, we had used the case of Santa Monica city to review 29 indicators as suggested by Tanguay et al, (2010). The case of Santa Monica has demonstrated that the six thematic dimensions of sustainable development are not sufficient to measure the years between 19902000. This exercise suggests that continuous data collection needs to be exploited to assist the development and assessment of indicators to achieve their local sustainable objectives. Indeed, in most cases, these indicators are subjective they can be revised to vary from one city to another. Significantly, there is a need to identify the practical application of sustainable indicators at local levels. This can be a challenge at the present time in some cases, though these challenges can be overcome with the suitable indicators to address sustainability in the future.

Consequently, the development of an appropriate framework for a sustainable city requires a tailor-made model that considers the needs of the locals in the city at the same time meet the sustainable efforts of its participants. On one hand, there are advantages in establishing sustainable indicators but on the other hand, such a task is challenging as stated by Stiglitz et al. (2009) in a dossier [16]. This calls for urban sustainability to include all stakeholders within the local areas and devise appropriate tools and framework. Another challenge facing sustainable indicators is the access to local data available to public and various stakeholders' objectives in communities. In addition, the end-use activities in this case, consumption, which are strongly linked to $\mathrm{CO}_{2}$ emissions and other pollutants, need specific local information. For instance, detailed data about industries such as manufacturing, oil and gas, roads and buildings in relation to sustainability at the local. Moussiopolous et al. (2010) highlighted one of the challenges in creating an efficient system of indicators is the selections of a manageable list of metrics to better describe sustainability. They further point out that developing indicators cannot be a purely technical or scientific process but should be an open communication and policy process [13]. In sum, it is recommended that future works include other cities in a comparison exercise using consistent sustainable indicators for the purpose of improving sustainable indicators for cities considering the socio-economic, political and environment conditions.

\section{Appendix}

Table.3. Description of sustainable dimensions found in Santa Monica progress report

\begin{tabular}{|c|c|c|c|}
\hline Indicator dimension & Categories & Indicator dimension & Categories \\
\hline \multirow[t]{8}{*}{ Resource conservation } & Ecological footprint & Housing & Affordable Housing \\
\hline & Energy Use & & $\begin{array}{l}\text { Affordable Housing for } \\
\text { Special Needs }\end{array}$ \\
\hline & Green Construction & & $\begin{array}{l}\text { Distribution of } \\
\text { Affordable Housing }\end{array}$ \\
\hline & $\begin{array}{l}\text { Green House Gases } \\
\text { Emissions }\end{array}$ & & Green Housing \\
\hline & Renewable Energy & & Livable Housing \\
\hline & Solid Waste & & \\
\hline & Sustainable Procurement & & \\
\hline & Water Use & & \\
\hline \multirow[t]{5}{*}{ Environmental and public health } & Air Quality & Transportation & $\begin{array}{l}\text { Alternative Fuel } \\
\text { Vehicles - City Fleet }\end{array}$ \\
\hline & $\begin{array}{l}\text { City Purchase of } \\
\text { Hazardous Materials }\end{array}$ & & $\begin{array}{l}\text { Average Vehicle } \\
\text { Ridership }\end{array}$ \\
\hline & Farmers' Market & & Bike Lanes \\
\hline & Food Choices & & Bus Ridership \\
\hline & Household Hazardous & & Pedestrian - Bike Safety \\
\hline
\end{tabular}




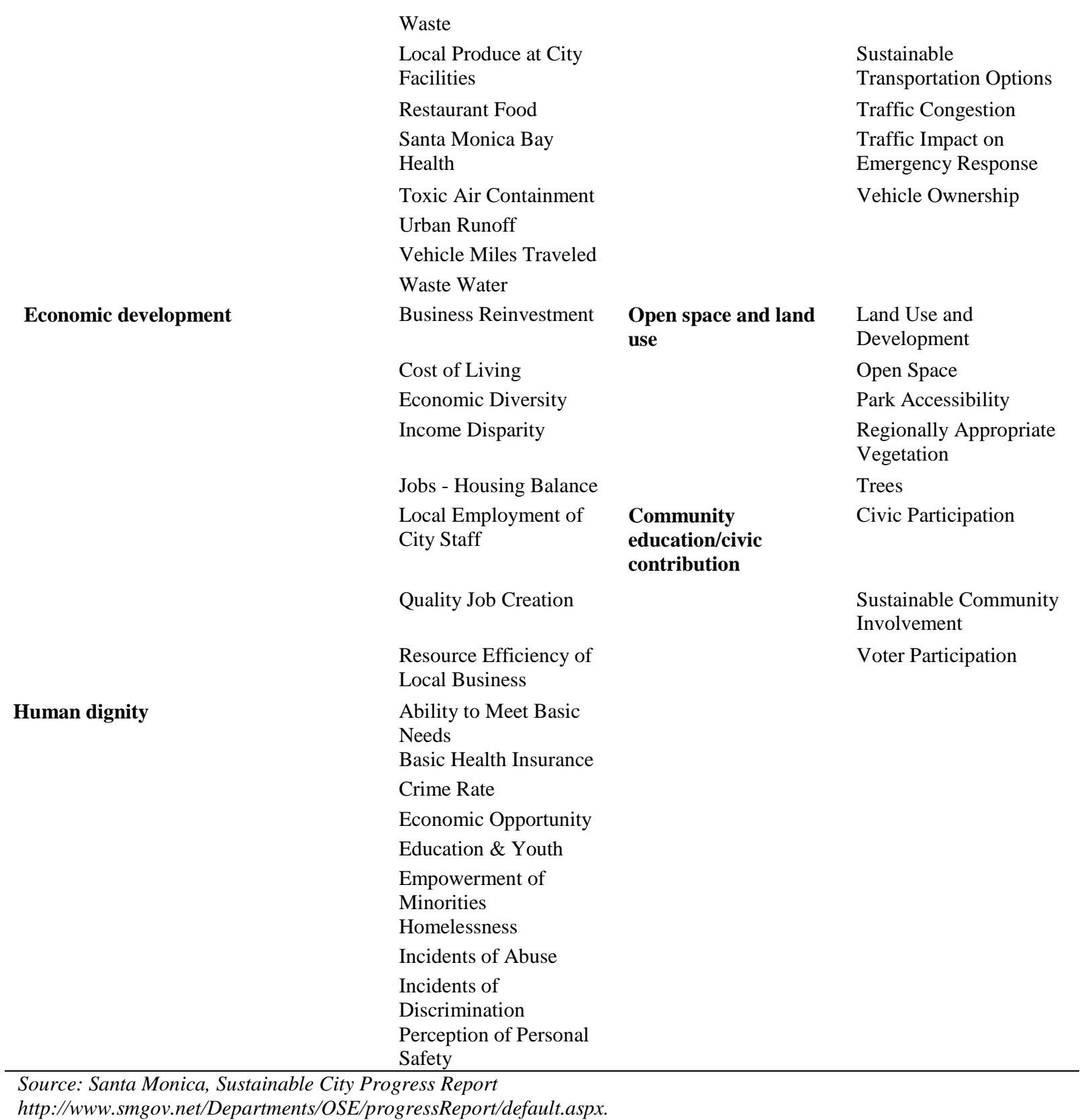

Table.4. Application of Sustainable development indicators (SDI) for the case of Santa Monica

\begin{tabular}{|c|c|c|c|c|c|}
\hline \multirow{2}{*}{\multicolumn{2}{|c|}{ Indicator }} & \multirow[b]{2}{*}{ Description } & \multicolumn{3}{|l|}{ SD } \\
\hline & & & Dimensions & 2000 & 1990 \\
\hline 1 & SD policies or strategies & yes / no & Sustainable & 1 & 0 \\
\hline 2 & Density of urban population & & Sustainable & n.a & n.a \\
\hline 3 & Daily water consumption per person & millions gallon per day & Sustainable & 13.2 & 14.2 \\
\hline 4 & Ecological footprint & per acres & Sustainable & 20.9 & 21.4 \\
\hline 5 & State of health reported by population (6) & percentage perception by & Sustainable & $16 \%$ & n.a \\
\hline 6 & Users of mass transit (MT) (8) & percentage of riders & Sustainable & & $9.10 \%$ \\
\hline 7 & Space alloted to nature conservation relative to area & percentage of open space to & Sustainable & $3.30 \%$ & $3.20 \%$ \\
\hline 8 & Cost of living & Cost living \$ per household & Economic & 79,890 & 55,300 \\
\hline 9 & Participation rate for all sectors & & Economic & $\mathrm{n} / \mathrm{a}$ & $\mathrm{n} / \mathrm{a}$ \\
\hline 10 & Job creation for all sectors (2) & number of jobs & Economic & 2113 & 1283 \\
\hline 11 & Mean or median household income per year & Median household (\$ / Yr.) & Economic & 50,714 & 35,997 \\
\hline 12 & Households spending $30 \%$ or more of income on & $\%$ Percent of rent-controlled & Equitable & $40 \%$ & $85 \%$ \\
\hline 13 & Population aged 18 and over with less than a high & & Equitable & n.a & n.a \\
\hline 14 & Unemployment rate & & Equitable & & \\
\hline 15 & Ratio, population with high income-low income & ratio of high-low & Equitable & 92.9 & 35.9 \\
\hline
\end{tabular}


16 Population receiving social assistance

17 Low-income households(3)

18 Crime rate (5)

19 Rate of participation in municipal elections

20 Citizen participation in public affairs (4)

21 Annual consumption of energy from renewable

22 Businesses with environmental certification

23 Quantity of waste recycled

24 Concentration of PM10 particles

25 GHG emissions (1)

26 Population exposed to Lnigh $>55 \mathrm{~dB}$ (A)

27 Quality of waterways

28 Quantity of household waste (7)

29 Participation in sports in parks \& swimming pools (9) \% of households $\%$

$\%$

$\%$

tonnes per year

per capita

tonnes per year percentage of households per capita crime rate

Notes:(1) Including transport (2) here only for 2005 (19\%) and 2006 (18\%) data, here the job creation 2113 (2005), 1283 (2006 (3) less than 25,000K US (4) only for 2002, for the year 1990 without considering other attributes such farmer's market, pier's concert and festivals (5) only for 2006 (4.35\%) and 2005 (4.51\%) (6) only for 2002, for the other years undetermined (7) for 1995 (275,842) for waste and recycled for 1995 (40,013) (8) for 2007 (9.1) and 2008 (9.2) (9) for 2005 only, not participation but access (10) open space for parks, public gathering, green streets, gardens and other public places 2006 (3.3) and 2004 (3.2\%) (11) for 1998 (85\%) and 2008(40\%).

\section{References}

[1] L. R. Brown, Plan B.4.0, Mobilizing to Save Civilization, Earth Policy Institute publication, W.W. Norton and Co: New York, 2009.

[2] M. Polase, Urban Population in 1900, Urbanization and Development, Development Express, no.4, 1997, U.N. Population Division, World Urbanization Prospectus: The 2007 Revision, UNPD: New York 2009.

[3] U.N. Population Division, World Urbanization Prospectus: The 2007 Revision Population Database, electronic database, 2007, available at: www.esa.un.org/unup.

[4] G. Metschies, Pain at the Pump, Foreign Policy, July/August 2007, World's Automotative Group, World Motor Vehicle Data: Southfield, Michigan, 2008

[5] A. R. Migiro, The U.N. Report on Water Crisis, U.N. Symposium on Water Security, News Services, 2009

[6] P. Anastasiadis and G. Metaxas, Environmental protection and the sustainable city, Proceedings of $1^{\text {st }}$ World Conference on Technology and Engineering Education, Kraków, Poland, 14-17 September, 2010 WIETE, pp. 91

[7] Sustainable city network (SCN), available at: www.sustainablecitiesnet.com.

[8] G. A. Tanguay, J. Rajaonson, J.F. Lefebvre and P. Lanoie, Measuring the sustainability of cities: An analysis of the use of local indicators, Ecological Indicators 10, 2010, pp. 407-418.

[9] Climate action, available from: http://www.climateactionprogramme.org/news.

[10] European Neighbourhood and Partnership Instrument, Strategy Paper (2007-2013), Eastern

Regional Programme, European Commission, available from:

http://ec.europa.eu/world/enp/pdf/country/enpi-eastern-rsp-en.pdf.

[11] L. Shen, J. Jorge Ochoa, Mona N. Shah, and Xiaoling Zhang, The application of urban sustainability indicators e A comparison between various practices, Elsevier, Habitat International 35, 2011, pp. 17-29.

[12] K. Zhang, X, He, and Z, Wen, Study of indicators of urban environmentally sustainable development in China, International Journal of Sustainable Development 6 (2), 2003, pp. 170-182.

[13] N. Moussiopoulos, C. Achillas, C. Vlachokostas, D. Spyridi, and K. Nikolaou, Environmental, social and economic information management for the evaluation of sustainability in urban areas: A system of indicators for Thessaloniki, Greece, Cities, 27, 2010, pp. 377-384.

[14] D., Niemeijer, R.S. De Groot, A conceptual framework for selecting environmental indicators sets. Ecological Indicators 8, 2008, pp. 14-25.

[15] Santa Monica Sustainable City Program - Progress Report Office of Sustainability and Environment, Santa Monica, US, 2009 available from: http://www.smgov.net/Departments/OSE/progressReport/default.aspx.

[16] Stiglitz, JE, Sen, A \& Fitoussi, JP. Report by the Commission on the Measurement of Economic Performance and Social Progress (Commission on the Measurement of Economic Performance and Social Progress, 2009. 